\title{
Mechanism and Control of Spalling for Friable Sandstone Pillars in a Room and Pillar Mine
}

\author{
Ding Ziwei ${ }^{1,2, *}$, Jia Jindui ${ }^{1}$, Bagherieh Amirhossein ${ }^{3}$, Li Ji $^{1}$ and Song Yue ${ }^{1}$

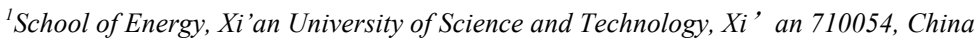 \\ ${ }^{2}$ Anhui Province Key Laboratory of Mining Response and Disaster Prevention and Control in Deep Coal Mine, Anhui University of \\ Science and Technology, Huainan 232001, China \\ ${ }^{3}$ Department of Mineral engineering, New Mexico Institute of Mining and Technology, Socorro, NM 87801, USA
}

Received 19 May 2018; Accepted 15 December 2018

\begin{abstract}
The ability to efficiently control sandstone pillar spalling is extremely important in ensuring the safety and highefficiency production of sandstone mines. The increase in size is usually suggested as a remedy for pillar spalling, but none of the suggested remedies reflect the influences of geotechnical properties of rock mass on stability control. Some sandstone mining practices have proven that increasing the size of pillars cannot effectively control pillar spalling. The relationship between the strength of St. Peter sandstone pillar and pillar loads was theoretically analyzed in the current study, in order to examine the influences of geotechnical parameters of sandstone on the stability of pillars and control pillar spalling. The key geotechnical parameters that influence the stability of sandstone pillars were also examined. Subsequently, the pillar instability mechanism and influences of geotechnical parameters on pillar stability were investigated by Finite Difference Method. Finally, a ground control method using shotcrete on pillar was proposed for increasing the stability of pillars. Results demonstrate that compressive stress on the St. Peter sandstone pillar is considerably larger than the compressive strength after mining, resulting in the evident deformation of most regions. The relation curves of displacement at the pillar top with internal friction angle and cohesion are in the power functional distributions, but the change of cohesion is more significant in the pillar strength. The displacement at the pillar top gradually decreases with the increase in internal friction angle, whereas the plastic failure regions of pillars gradually decrease from the bottom to the upper parts with the increase in cohesion. A field industrial test proves that shotcrete on pillars can increase pillar strength, which effectively controls the pillar spalling. Research results provide theoretical and practical guidelines to enhance the stability of pillars under the same geotechnical circumstances.
\end{abstract}

Keywords: Room and pillar mining, Pillar spalling, Cohesion, Internal friction angle

\section{Introduction}

As an underground mining technique that is environment friendly, room and pillar mining has been widely used in America and Australia. The core of the room and pillar mining system is to mine rooms according to the design and leave pillars to support and control the roof and surface subsidence [1-2]. Pillar stability is the key element of safe room and pillar mining. Pillar spalling is one of the typical instability forms of sandstone; therefore, controlling pillar spalling is crucial in ensuring the safe and high-efficiency production of sandstone mines [3].

In ground control, room and pillar mining is believed to alter the in situ state of stress in strata, and stress overlying strata can be transferred to the adjacent pillars after room and pillar mining. Consequently, room and pillar mining results in increasing stress on the pillars. Meanwhile, the horizontal deformation of pillars induced by the external effect is free of constraints due to the presence of rock masses on both sides after room mining, thus decreasing pillar strength accordingly. Hence, the rock mass of pillars

\footnotetext{
*E-mail address: zwding519@163.com

ISSN: $1791-2377$ @ 2018 Eastern Macedonia and Thrace Institute of Technology. All rights reserved.

doi:10.25103/jestr.116.25
}

develops deformation failures. Pillar instability control depends on the retention of the reasonable size and shape of pillars so that they can endure mining-induced stresses [4-6]. Size effect theory of rock mass indicates that rock mass failure is mainly caused by the development of the structural surface in rock mass and the failure of the weakest structural surface. When the pillar size is increased to a certain critical value, the rock strength remains constant with the increase in pillar size. The pillar strength is equal to rock mass strength under this critical size. Based on several engineering practices, pillar stability control is accomplished by designing reasonable pillar size according to the critical pillar strength. Although this theory is simple, the influences of the geotechnical parameters of rock mass on pillar instability are neglected for the pillar strength analysis, thus failing to achieve a good ground control result for some rock mining practices.

Compared with size effect theory, two-region constraint theory involves the influences of the internal friction angle of coals. According to this theory, a central elastic zone and two-side yield zones are formed in pillars after mining. The central elastic zone is compressed in three directions due to constraints from the two-side yield zones. Two-region constraint theory estimates pillar strength based on the threedirectional strength characteristics. Although this method 
Ding Ziwei, Jia Jindui, Bagherieh Amirhossein, Li Ji and Song Yue/

Journal of Engineering Science and Technology Review 11 (6) (2018) 197 - 205

has been used extensively, the influences of cohesion on pillar strength are neglected.

Owing to disturbances caused by room and pillar mining, the different degrees of stress concentration develop between St. Peter sandstone pillars and cap rocks in Pattison Mine, which further cause many large-scaled instability behaviors, including pillar spalling and collapse. Changing pillar size during mining fails to control the pillar -spalling behavior effectively. St. Peter sandstone has extremely high internal friction angle (in the range of $57^{\circ}-69^{\circ}$ ) and is virtually cohesionless [7-9]. The high internal friction angle makes sandstone pillars bear extremely high loads under small deformation, whereas the low cohesion leads to extremely weak sandstone pillars after mining disturbances. Therefore, internal friction angle and cohesion can both considerably influence the mechanism of St. Peter sandstone pillar instability. Thus, the pillar stability control cannot be accomplished without consideration to internal frictional angle and cohesion.

In the current study, the influences of the geotechnical properties of St. Peter sandstone in Pattison Mine on the deformation failure of pillars were studied using theoretical analysis and finite difference numerical simulation. The pillar spalling mechanism was disclosed, and special ground control measures were proposed.

\section{State of the art}

Traditional theories of pillar stability state that controlling pillar stability in room and pillar mining is performed by increasing the strength of pillars and their ability to bear mining-induced loads. Studies on pillar strength characteristics based on laboratory tests, theoretical analyses, and numerical simulations have been reported, and some calculation methods of pillar size applicable to engineering design have been developed to control pillar spalling. However, these studies mainly focus on the influences of rock mass size on failure mode, ultimate bearing capacity, and load-deformation process of pillars. For example, Renani et al. [10] studied the progressive failure of hard rock pillars using two- and three-dimensional finite difference analysis. The stress-strain curves indicated that pillars exhibited strain-softening behavior when the width/height ratio of pillars was lower than 2 and strain-hardening behavior when the width/height ratio was higher than 2 . Moreover, a constitutive model on progressive damages of rock mass in pillars, which considered cohesion weakening and friction strengthening in rock mass, was proposed in numerical calculation. Poulsen et al. [11-12] introduced a stress calculation method that considered the shape and spatial position of pillars. In addition, 120 groups of numerical models were constructed through finite difference analysis to study pillar stability under filling effect of roadways. They found that pillar strength was directly related with filling degree and that viscous filling body increased the pillar strength.

Meanwhile, the influences of filling parameters on pillar strength have been discussed through numerical calculation by adjusting cohesion in the constitutive model, whereas those of coal parameters were neglected. Yang et al. [13] proposed a formula of full-scale mine pillar strength based on laboratory scale strength obtained from specimens. The pillar size calculated by this formula ensured pillar stability when the width/height ratio of pillars ranged within $0.6-0.8$ and the safety coefficient was higher than 1.5. Moreover, rock mass, pillar conditions, mining size, and complete rock strength were considered during calculation. Guy et al. [14] indicated that the stability of the pillar system was related to the post-failure stiffness of the pillar and its interaction with overburden stiffness. They also found that the post-failure stiffness of pillars was a function of pillar width/height ratio. In addition, they examined the influences of pillar size and shape on pillar system during the stability evaluation of the system, except for the relationship between loads of overlying strata and pillar strength. Jaiswal et al. [15] considered coal as a Hoek-Brown strain-softening material and proposed a formula to estimate pillar strength during mining of India Mine based on Finite Element Method. In this formula, the extension deformation of pillars is the function of confining pressure and plastic shear strain. The numerical calculation model was also calibrated by using data from actual mining situations of India Mine. Kaiser et al. [16] found that the pillar strength in the core region estimated by the Mohr-Coulomb or Hoek-Brown criteria was lower than the actual pillar strength, and that the pillar size designed according to existing empirical formula for controlling pillar stability was poor. Moreover, the S-shaped criteria of the rock mass failure of pillars were proposed to construct the constitutive relationship for numerical calculation, which could increase the evaluation accuracy of pillar strength. Based on a case study of rock mining in America, Dolinar et al. [17-18] proposed an estimation formula of pillar strength and provided suggestions for good pillar designs. Although this formula and relevant suggestions considered the potential influences of rock discontinuity on pillar strength, they were based on experiences of rock room mining in America and could only be directly applied to pillar design under similar conditions. Meanwhile, Walton et al. [19] constructed a constitutive model to describe strength and dilatancy deformation of brittle rocks based on laboratory test data. Simultaneously, the surrounding stress and deformation distributions of the shaft were predicted through numerical calculation. Song et al. [20-21] analyzed the sensitivity of influencing factors of pillar stability based on an orthogonal test. The major influencing factors of pillar instability were also evaluated from pillar loads, pillar strength, pillar instability form, and determination of influencing factors. Nevertheless, the influences of geotechnical parameters on pillar strength were ignored. Jiang et al. [22] conducted a uniaxial compressive numerical simulation test of pillars using FLAC3D and analyzed the stress-strain curve characteristics of the pillar system at the instability failure. Through the calibration of coal samples, the simulation of brittle failure was controlled by changing cohesion, internal friction angle, and expansion angle, with considerations to influence the geotechnical parameters on the constitutive relationship. Through field measurement and theoretical analysis, Fu et al. [23] studied the occurrence mechanism and prevention measures of dynamic load pressure by analyzing critical elastic core width for small pillars to maintain stability under lead abutment pressure, overlying structure, and support loads on the working surface under dynamic loads. Although the rotation effects of overlying strata on pillars were considered, influences of pillar strength were neglected. The aforementioned studies have discussed the influences of pillar size, shape, and constitutive relations on pillar strength and analyzed failure mode, bearing capacity, and instability factors of pillars. However, none of these studies have discussed the influence mechanism of the mechanical performances of rock mass materials on pillar spalling. 
Ding Ziwei, Jia Jindui, Bagherieh Amirhossein, Li Ji and Song Yue/

Journal of Engineering Science and Technology Review 11 (6) (2018) 197 - 205

To further frontier knowledge of pillar stability analysis, the correlation between pillar strength and pillar loads was analyzed theoretically, and the key geotechnical parameters of St. Peter sandstone pillar stability were determined in the present study. Therefore, the influences of key geotechnical parameters on pillar stability were analyzed utilizing finite difference analysis, thus allowing us to explain the pillar instability mechanism from the perspective of geotechnical parameters and propose relevant countermeasures. The results were verified by numerical simulation and field test. This study provides theoretical and practical bases for stability control of similar sandstone pillars.

The remainder of this study is organized as follows. Section 3 introduces the project, numerical modeling, and key geotechnical parameters of pillar stability control. Section 4 analyzes pillar strength under the influences of key geotechnical parameters and discusses the influences of cohesion, internal friction angle, plastic region, and vertical stress distribution of pillars. The program for the improvement of pillar stability control is formulated, and control effect is verified. Section 5 presents the conclusions.

\section{Methodology}

\subsection{Theoretical analysis of pillar stability}

Understanding the relationship between pillar strength and pillar loads is the key to investigating pillar failure during room and pillar mining [24]. Pillar instability occurs if the pillar strength is smaller than pillar loads; otherwise, the pillar will remain stable. Therefore, the relationship between pillar strength and pillar loads was theoretically analyzed to determine the influencing factors of stability of St. Peter sandstone pillars.

\subsubsection{Pillar loads}

Pillar load is usually calculated by the tributary area method in room and pillar mining. This method assumes that during horizontal mining with adequate mining areas, pillars with the same shape have equal strength and bear the same loads [25-26]. The loads on rectangle pillars could be calculated by using Eq. (1)

$$
P=\gamma h(W+b)(l+b)
$$

Where $P$ is the pillar load (MPa), $\gamma$ is the unit weight of overlying strata $\left(\mathrm{MN} / \mathrm{m}^{3}\right), h$ is the mining depth $(\mathrm{m}), W$ is pillar width $(\mathrm{m}), l$ is the pillar length $(\mathrm{m})$, and $b$ is the room width $(\mathrm{m})$.

\subsubsection{Pillar strength}

In the mechanics of materials, loads on beams are calculated by the integration of the area below the stress curve. Pillars must be in the elastic core region for room and pillar mining in order to maintain pillar stability. The stress in the core region is hypothesized to reach the peak stress. The stress distribution curve on a pillar is given in Fig. 1.

The bearing capacity (L) of the pillar is expressed as

$$
L=4 \times W \int_{0}^{\hat{y}} \sigma_{V} d y+(W-2 \hat{y})^{2} \times \hat{\sigma}_{V}
$$

Where $y$ is the distance to the pillar edge $(\mathrm{m}), \hat{y}$ is the width of plastic region $(\mathrm{m}), \sigma_{V}$ is the vertical stress at the place $\mathrm{y}$ away from the pillar edge $(\mathrm{MPa})$, and is the maximum vertical stress $(\mathrm{MPa})$.

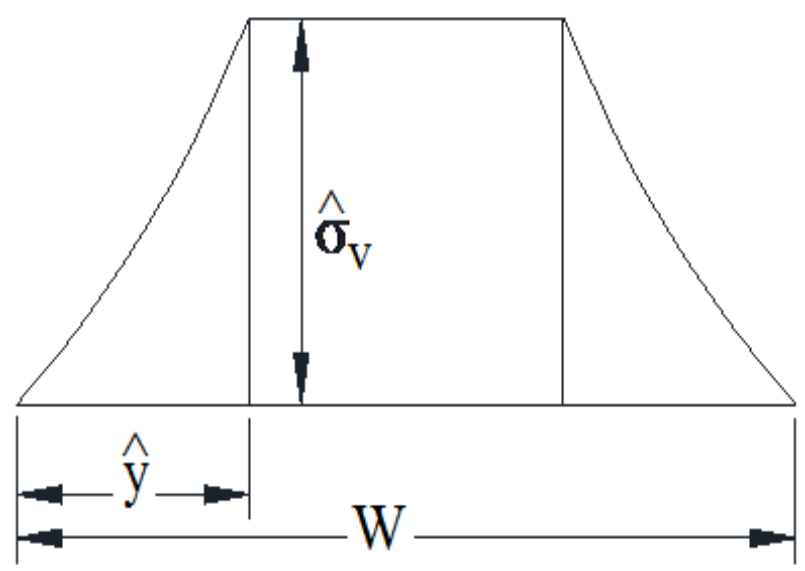

Fig. 1. Stress distribution in pillar

By integration of Eq. (2), it is simplified into

$$
\begin{aligned}
& L=\frac{2 W M \sigma_{0}}{\tan \phi \tan \beta}\left(e^{T}-1\right)+(W-2 \hat{y})^{2}\left(\sigma_{0}+\gamma h \tan \beta\right) \\
& T=\frac{2 \tan \phi \tan \beta}{M} \hat{y}
\end{aligned}
$$

where $M$ is the height of the pillar (m), $\sigma_{0}$ is the uniaxial compressive strength (MPa), is the coefficient of horizontal pressure, and is the internal friction angle of the pillar.

\subsubsection{Safety factor of the pillar}

The safety factor (SF) should be satisfied to maintain the stability of sandstone pillars using Eq. (5) below.

$$
S F=\frac{L}{P} \geq 1
$$

Eq. (4) shows that the SF of the pillar is influenced by stress state, geometric parameters, cohesion, and internal friction angle of the pillar. However, stress state and geometric parameters of the pillar are determined by field production technological conditions. Given that St. Peter sandstone has special mechanical properties, the influences of these mechanical properties on the stability of sandstone pillars are also remarkable. Therefore, studying the influencing mechanism of cohesion and internal friction angle on the stability of sandstone pillars provides important theoretical references to the control of pillar stability.

\subsection{Finite difference numerical simulation}

\subsubsection{Introduction to the project}

In this study, a numerical simulation analysis based on the actual mining of Pattison Mine was conducted. A total of 20 $\mathrm{m} \times 20 \mathrm{~m}$ pillars remained in the Pattison Mine. Room width, mining depth, and mining height were 10, 44, and $9 \mathrm{~m}$, respectively. During the mining process, different degrees of surface spalling were observed on the pillar surface between the upper part of St. Peter sandstone pillars and cap rocks as a response to the mining, which further evolved into a smallscaled pillar scaling. The failure mode of St. Peter sandstone pillars was manifested by inward stratified spalling by stress 
Ding Ziwei, Jia Jindui, Bagherieh Amirhossein, Li Ji and Song Yue/

Journal of Engineering Science and Technology Review 11 (6) (2018) 197 - 205

concentration. Different from the overall slippage of common pillars caused by plastic failure, the failure mode of St. Peter sandstone pillars was similar to the plate or stratified failure of stratified rock mass under comprehensive effects.

\subsubsection{Finite difference numerical simulation modeling}

A FLAC3D numerical simulation model (Fig. 2) was constructed based on the actual geometric and geotechnical parameters of St. Peter sandstone rooms in Pattison Mine. Stress, displacement, and the plastic failure of pillars were analyzed based on this model. Height and width of the constructed FLAC3D model were 13.11 and $30 \mathrm{~m}$, respectively. The room and pillar widths were 10 and $20 \mathrm{~m}$, respectively.

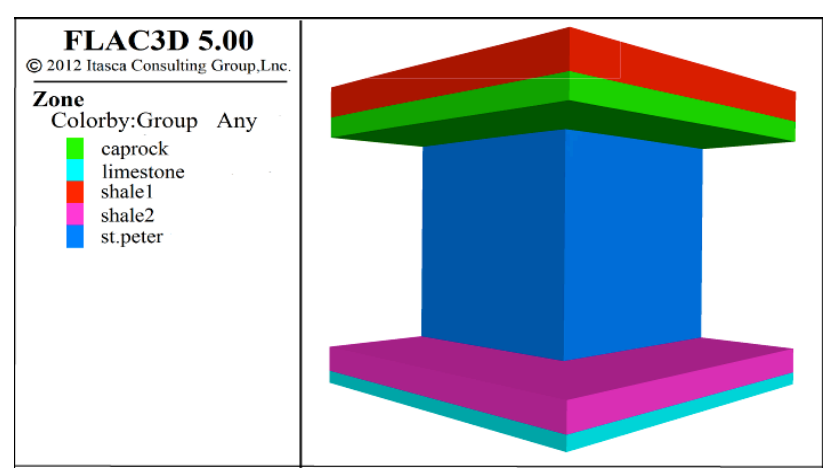

Fig. 2. Numerical simulation model

Horizontal displacement constraints were applied at two sides of the calculation model, whereas a vertical displacement constraint was applied at the bottom. A 1.1 $\mathrm{MPa}$ vertical load of overlying strata was applied at the top of the model. The in situ stress was applied according to the empirical formula of $2.5 \mathrm{MPa} / 100 \mathrm{~m}$. Rectangle grids were also used. The grid size on the pillar was $0.25 \mathrm{~m} \times 0.25 \mathrm{~m} \times$ $0.25 \mathrm{~m}$, and the grid size at roof and floor was $0.5 \mathrm{~m} \times 0.5 \mathrm{~m}$ $\times 0.6 \mathrm{~m}$. The Mohr-Coulomb criterion was chosen as the constitutive model. A quarter of the pillar was also chosen in the calculation, and strata with similar lithology or thin strata were combined. The model was simplified into four rock layers, including St. Peter Sandstone (pillar), shale (roof and floor), cap rocks (roof), and limestone (floor). The mechanical parameters of different rock layers are listed in Table 1.

Contours of stress, plastic region, and displacement distribution of pillars were obtained by numerical simulation (Fig. 3). As shown in Fig. 3(a), tensile stress regions are found at the roof and floor of pillars, whereas the pillar is completely observed in the compressive stress regions. Moreover, an evident small-scaled stress concentration is observed at the corner of the pillar-cap rock interface. However, stress concentration also occurs in other regions on the interface, and the maximum vertical stress reaches approximately $20 \mathrm{MPa}$, which is considerably higher than the compressive strength of St. Peter sandstone. The distribution of plastic regions in Fig. 3(b) demonstrates the evident formation of compression-shearing failure downward from the sandstone-cap rock interface because sandstone pillar is basically influenced by the compressive stress, which is considerably higher than compressive strength of sandstone. Furthermore, the plastic region presents an evident "X-shaped" distribution pattern. According to the contour of vertical displacement distribution in Fig. 3(c), regions with shearing failure on the pillar are substantially deformed, and the displacement distribution is in an evident "concave" pattern. The deformation in the pillar-cap rock interface is the highest, reaching $30 \mathrm{~mm}$.

Based on the preceding analysis, the St. Peter sandstone pillar is generally in the compressive stress region after mining, and the compressive stress is considerably higher than compressive strength of the pillar, thus resulting in evident large-scaled deformation and compression-shearing failures of the pillar. An "X-shaped" plastic region is also formed.

Table. 1. Mechanical parameters

\begin{tabular}{|c|c|c|c|c|c|c|}
\hline Lithology & Density $/ g / \mathbf{m}^{3}$ & $\begin{array}{l}\text { Bulk modulus / } \\
\text { GPa }\end{array}$ & $\begin{array}{l}\text { Shear modulus / } \\
\text { GPa }\end{array}$ & $\begin{array}{l}\text { Internal friction } \\
\text { angle } /^{\circ}\end{array}$ & Cohesion / MPa & $\begin{array}{l}\text { Tensile strength } \\
\text { /MPa }\end{array}$ \\
\hline Shale & 2350 & 8.8 & 4.3 & 25 & 2.0 & 1.39 \\
\hline Cap rock & 2200 & 20 & 7.0 & 35 & 4.0 & 2.39 \\
\hline St. Peter & 1900 & 1.4 & 0.8 & 60 & 0.6 & 0.87 \\
\hline Limestone & 2600 & 22.6 & 11.1 & 30 & 6.0 & 4.39 \\
\hline
\end{tabular}

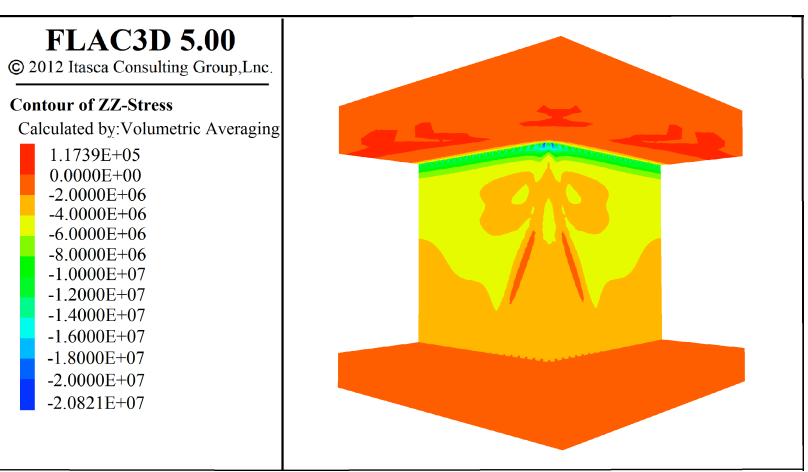

(a)

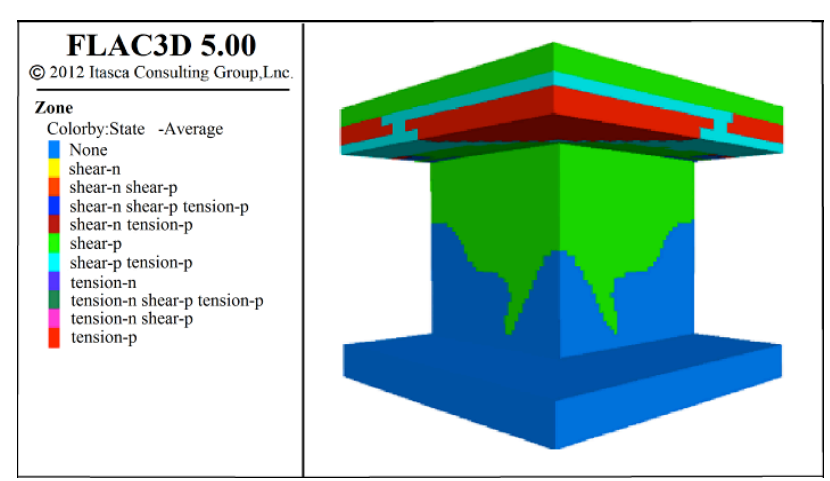

(b) 
Ding Ziwei, Jia Jindui, Bagherieh Amirhossein, Li Ji and Song Yue/

Journal of Engineering Science and Technology Review 11 (6) (2018) 197 - 205

\begin{tabular}{|c|}
\hline $\begin{array}{c}\text { FLAC3D 5.00 } \\
\text { 2012 Itasca Consulting Group,Lnc. }\end{array}$ \\
\hline 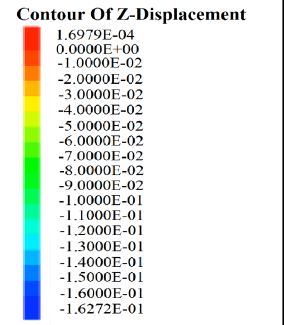 \\
\hline
\end{tabular}

Fig. 3. Contour of pillars. (a) Vertical stress contour. (b) Plastic region contour. (c) Vertical displacement contour.

\section{Test results and analysis}

The theoretical analysis of pillar stability reveals that cohesion and internal friction angle are two important influencing factors of stability of the St. Peter Sandstone pillar. The variation of stress state, plastic region distribution, and displacement distribution of the St. Peter sandstone pillar with cohesion and internal friction angle were analyzed by the FLAC3D finite difference numerical simulation. The numerical simulation model only changed the cohesion and internal friction angle but had consistent rock and simulation parameters with those in common models.

\subsection{Effects of internal frictional angle on pillar stability} With the internal frictional angles of St. Peter sandstone ranging between $57^{\circ}-63^{\circ}$, stress, plastic region, and displacement distributions of St. Peter sandstone under different internal frictional angles $\left(40^{\circ}, 50^{\circ}, 60^{\circ}\right.$, and $\left.70^{\circ}\right)$ were simulated.

The distributions of the plastic region and stress on St. Peter sandstone pillar under different internal frictional angles $\left(40^{\circ}, 50^{\circ}, 60^{\circ}\right.$, and $\left.70^{\circ}\right)$ are shown in Fig. 4. From the stress contours, the pillar is observed to be generally compressed under different internal frictional angles, accompanied by stress concentration in the pillar-cap rock interface. As can be seen, stress concentration intensifies with the increase in internal frictional angle. In the distribution contours of plastic regions, the St. Peter sandstone pillar develops evident plastic failure under different internal frictional angles, which is dominated by compression-shearing failure. Almost all pillars develop plastic failures at $40^{\circ}$. With the increase in internal frictional angle, the plastic failure scope of pillars gradually narrowed from bottom to up. A small-scale plastic region is formed at the corner of pillar-cap rock interface when the internal frictional angle is increased to $70^{\circ}$.

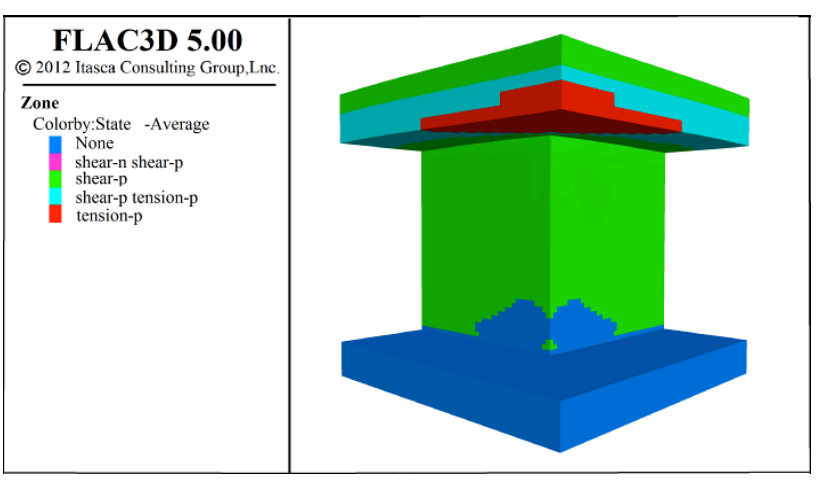

(a)

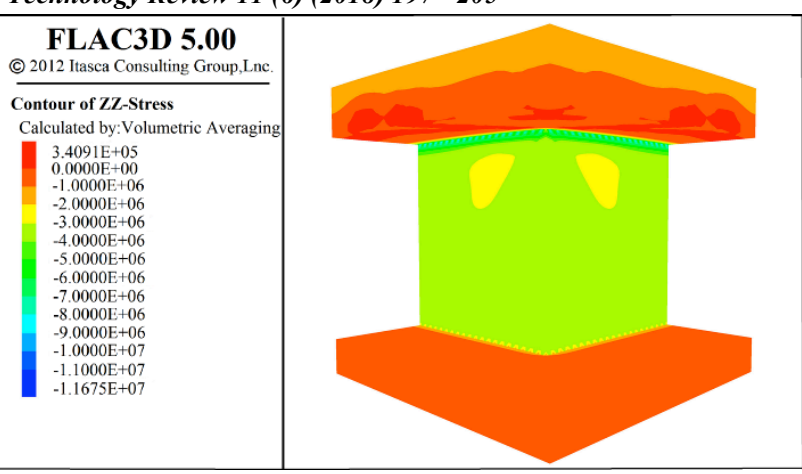

(b)
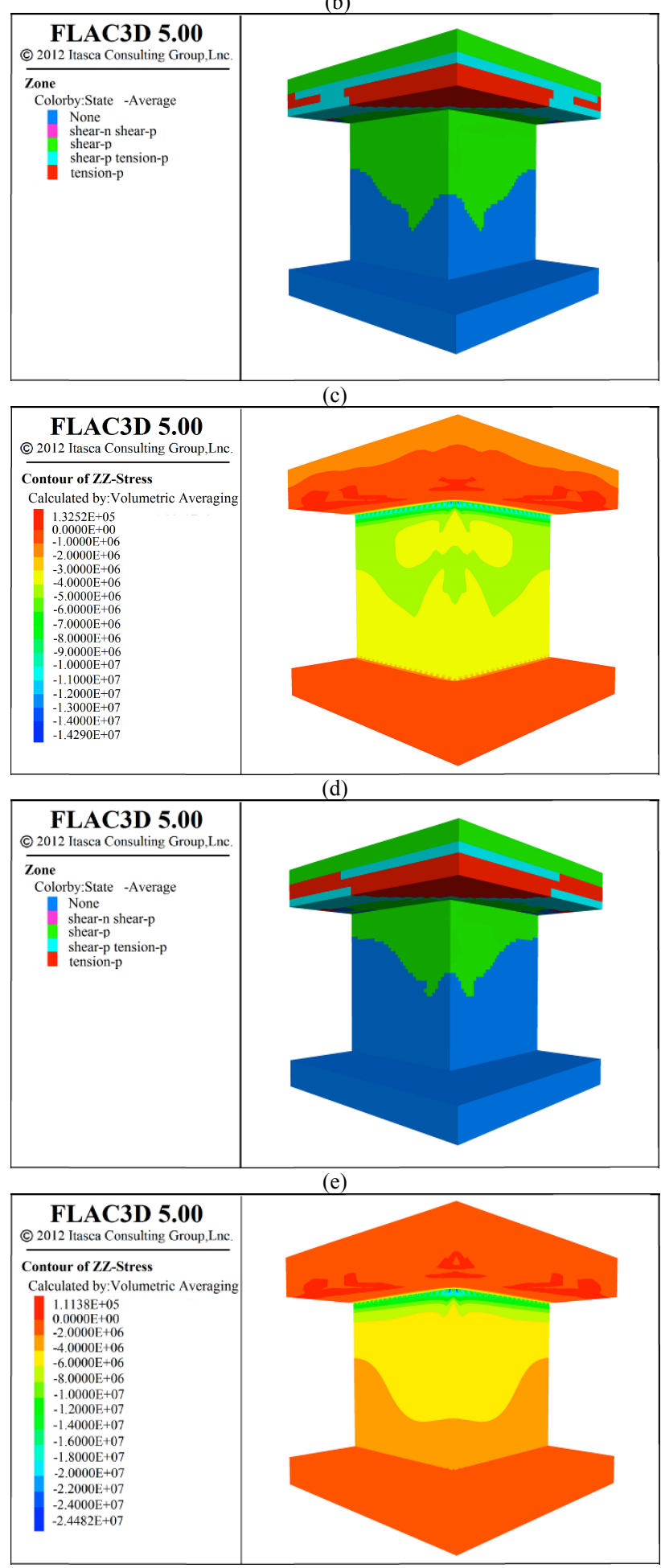

(f) 
Ding Ziwei, Jia Jindui, Bagherieh Amirhossein, Li Ji and Song Yue/

Journal of Engineering Science and Technology Review 11 (6) (2018) 197 - 205
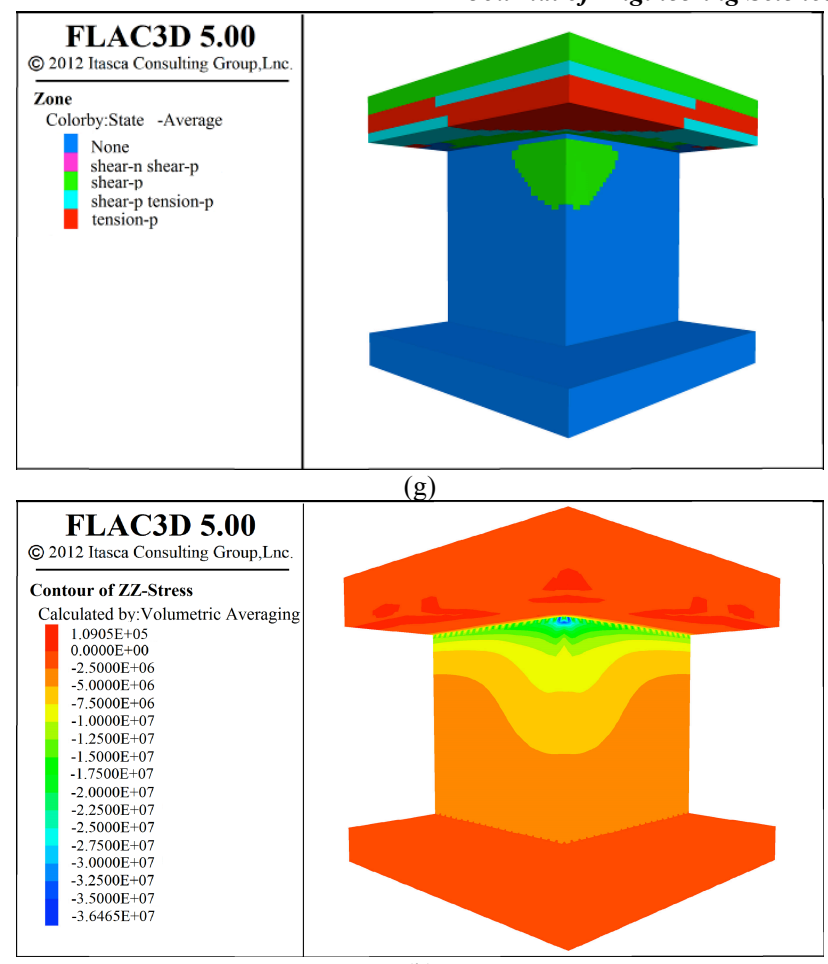

(h)

Fig. 4. Plastic region and stress distribution on pillars under different internal friction angles. (a) Plastic region $\left(\varphi=40^{\circ}\right)$. (b) Vertical stress $\left(\varphi=40^{\circ}\right)$. (c) Plastic region $\left(\varphi=50^{\circ}\right)$. (d) Vertical stress $\left(\varphi=50^{\circ}\right)$. (e) Plastic region $\left(\varphi=60^{\circ}\right)$. (f) Vertical stress $\left(\varphi=60^{\circ}\right)$. (g) Plastic region $\left(\varphi=70^{\circ}\right)$. (h) Vertical stress $\left(\varphi=70^{\circ}\right)$.

The relation curves between displacement at the measuring points at the pillar top and the internal friction angle were drawn according to the numerical simulation results of pillar displacement distribution, in order to further analyze the influences of internal friction angle on pillar stability (Fig. 5). These relation curves are approximately a power functional distribution. Displacement at the pillar top is gradually decreased with the increase in internal friction angle. The displacement reduction is outstanding when the internal friction angle increases from $40^{\circ}$ to $60^{\circ}$, but the reduction amplitude gradually declines after $60^{\circ}$. This finding indicates that the internal frictional angle affects deformation of sandstone pillars mostly in the range of $40^{\circ}$ $60^{\circ}$.

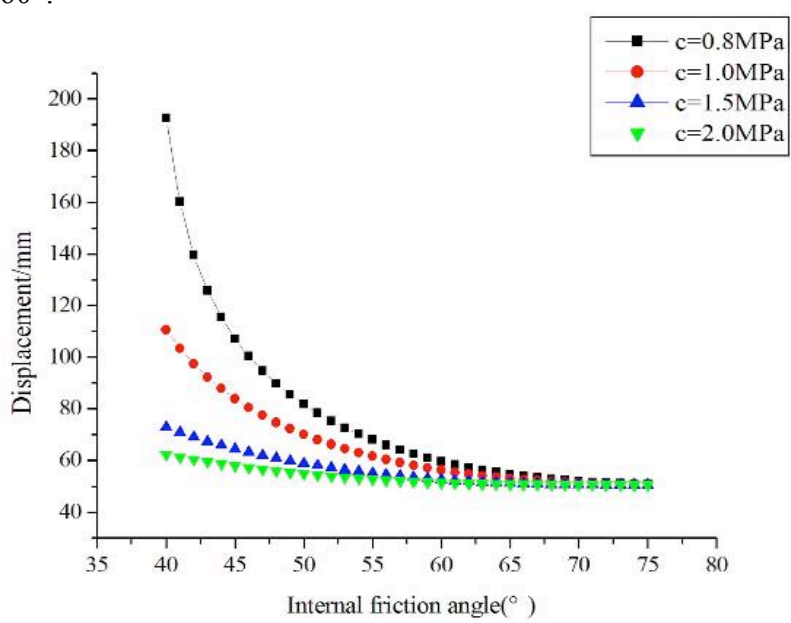

Fig. 5. Relation curves between internal friction angle and displacement at the top of pillar

\subsection{Effects of cohesion on pillar stability}

Given that the cohesion of the St. Peter sandstone is small, influencing laws of cohesion on sandstone pillar stability were investigated by gradually increasing cohesion. Stress, plastic region, and displacement changes of sandstone pillars under different cohesion values $(0.8,1.2,1.6,2.0$, and 2.4 $\mathrm{MPa})$ were simulated by FLAC3D.

The respective distributions of plastic regions and stress on pillars when cohesion values are $0.8,1.6$, and $2.4 \mathrm{MPa}$ are shown in Fig. 6. The stress contours under different cohesion show that pillars are generally compressed under different cohesion, and evident stress concentration also occurs in the pillar-cap rock interface, which is similar to that caused by changes of internal friction angle. Hence, the stress concentration degree is increased as the cohesion continuously increases. However, the stress concentration degree caused by the increase in cohesion is considerably higher than that caused by the increase in internal friction angle.

The distribution of plastic regions under different cohesion values is shown in Fig. 6. As can be seen, all pillars develop evident plastic failures under different cohesion values, which are dominated by compression-shear failures. However, the plastic failure range of sandstone pillars is considerably smaller than that caused by internal friction angle. The upper part of pillars develops plastic failure when the cohesion is $0.8 \mathrm{MPa}$. The plastic failure range of pillar is narrowed from the bottom to top as cohesion gradually increases. When the cohesion is increased to $2.4 \mathrm{MPa}$, only a small-scaled plastic region is formed at the corner of the pillar-cap rock interface.

The relation curves between displacement at measuring points at the pillar top and cohesion were drawn according to numerical simulation results of the pillar displacement distribution, in order to analyze the influences of cohesion on pillar stability (Fig. 7). These curves are approximately a power -functional distribution. The displacement at the pillar top is negatively correlated with cohesion. Such a displacement is remarkably decreased when cohesion increases from 0 to $1.4 \mathrm{MPa}$, but the reduction amplitude declines after 1.4 MPa. This finding indicates that cohesion influences the deformation of sandstone pillar mostly when it increases from 0 .

\subsection{Pillar scaling control}

\subsubsection{Control measures}

Based on the preceding analyses, the distribution range of the plastic region and that of pillars both considerably decrease with the increase in internal friction angle and cohesion, thus improving pillar stability. Therefore, the stability of St. Peter sandstone pillars can be increased by aggregating the cohesion and internal frictional angle.

Although aggregating the internal friction angle and cohesion can realize the goal of increasing pillar stability, the internal friction angle of St. Peter sandstone is high and aggregating the internal friction angle cannot considerably improve pillar stability. Nevertheless, the cohesion of the St. Peter sandstone is low (almost 0 ). Increasing cohesion alone can remarkably improve pillar stability. Finally, the cohesion of the surface sandstone of pillars can be increased by shotcrete, thus enabling the increase in pillar stability. 
Ding Ziwei, Jia Jindui, Bagherieh Amirhossein, Li Ji and Song Yue/

Journal of Engineering Science and Technology Review 11 (6) (2018) 197 - 205
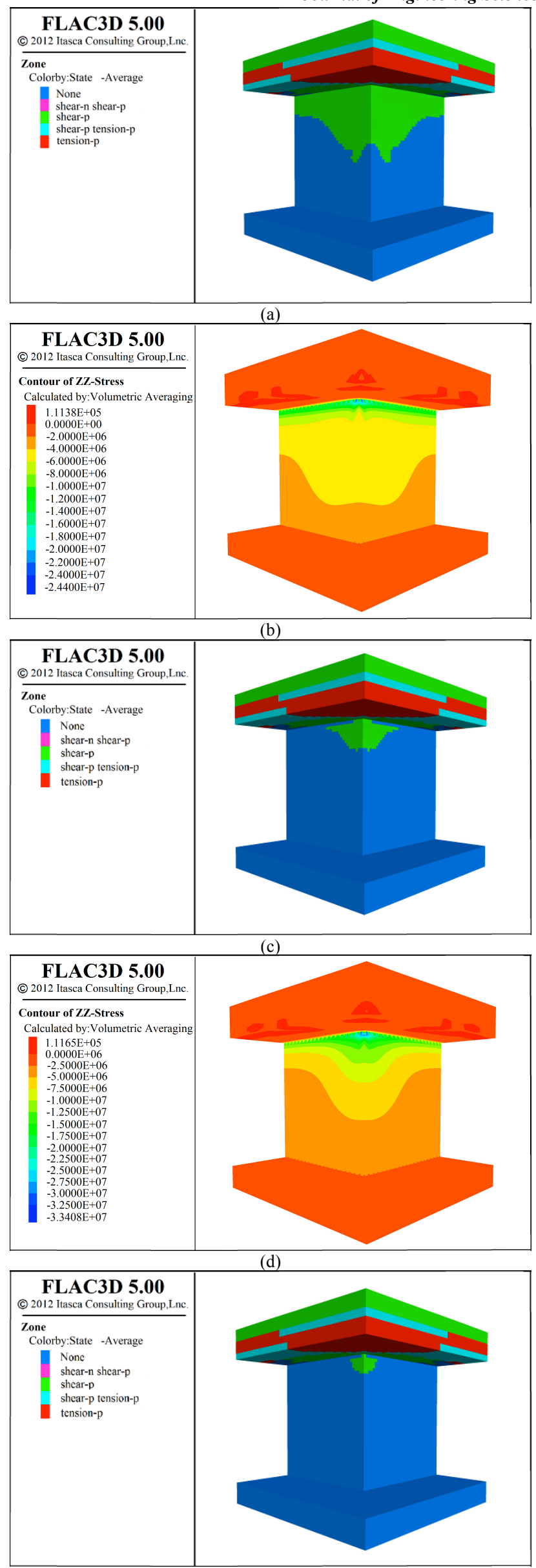

(e)
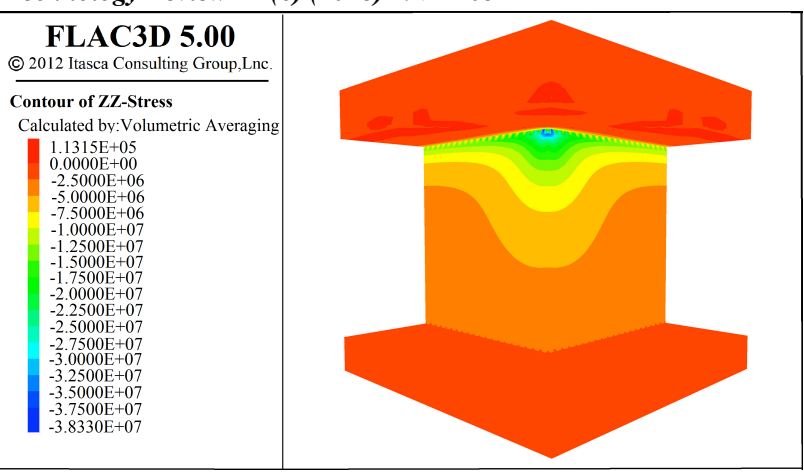

(f)

Fig. 6. Plastic region and stress distribution on pillars under different cohesion. (a) Plastic region $(c=0.8 M P a)$. (b) Vertical stress ( $c=0.8 M P a)$. (c) Plastic region $(c=1.6 M P a)$. (d) Vertical stress $(c=1.6 M P a)$. (e) Plastic region $(c=2.4 M P a)$. (f) Vertical stress $(c=2.4 M P a)$.

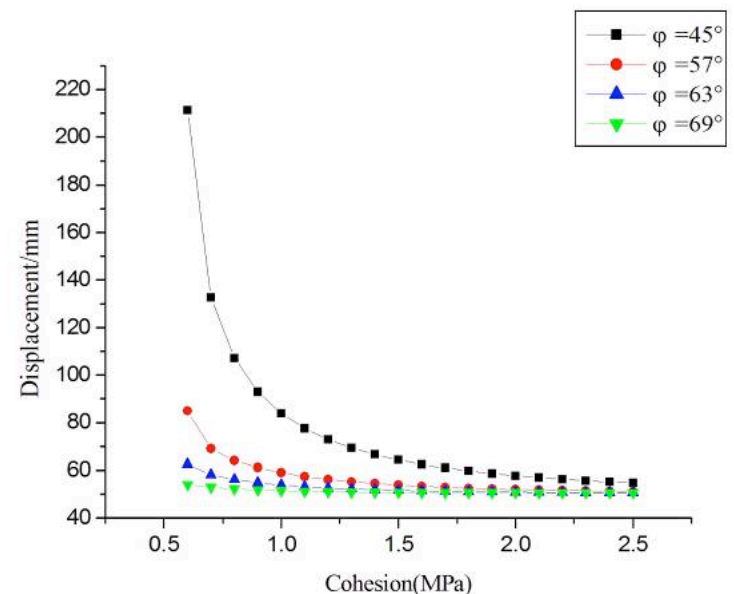

Fig. 7. Relation curves between cohesion and displacement at pillar top

\subsubsection{Control program}

According to the proposed control measures of sandstone stability, the shotcrete parameters are defined as follows:

(1) Given that St. Peter sandstone has high internal friction angle and low cohesion, a concrete layer was sprayed to the failure region of pillars as a form of support. The concrete strength was $20 \mathrm{MPa}$, and the concrete thickness was $10 \mathrm{~mm}$. The shotcrete was accomplished twice, and the concrete mixing ratio was cement: sand: gravel: accelerator $=1: 2: 2: 0.03$ (weight ratio).

(2) Spraying shotcrete shall be performed from top to bottom and from the pillar scaling region to other regions. At concrete spraying, the nozzle is perpendicular to the sprayed surface, and the distance is controlled within 0.6-1.2 $\mathrm{m}$. The concrete surface shall be kept smooth and bright with no dry spots and slippage after spraying.

\subsubsection{Numerical simulation of the spraying effect}

A FLAC3D numerical simulation analysis of the distributions of plastic regions and the displacement on sprayed sandstone pillars was conducted based on the proposed spraying program. The results are shown in Fig. 8. The plastic region is clearly remarkably narrowed after spraying shotcrete, accompanied by evident plastic failures of surrounding rocks at pillar corners. However, no evident large-scaled plastic region is formed in other regions. Simultaneously, the maximum displacement of pillars decreases from $211 \mathrm{~mm}$ before spraying to $92 \mathrm{~mm}$. 
Ding Ziwei, Jia Jindui, Bagherieh Amirhossein, Li Ji and Song Yue/

Journal of Engineering Science and Technology Review 11 (6) (2018) 197 - 205

Therefore, spraying shotcrete on the surface of sandstone pillars is a reasonable and feasible scheme to increase pillar stability.
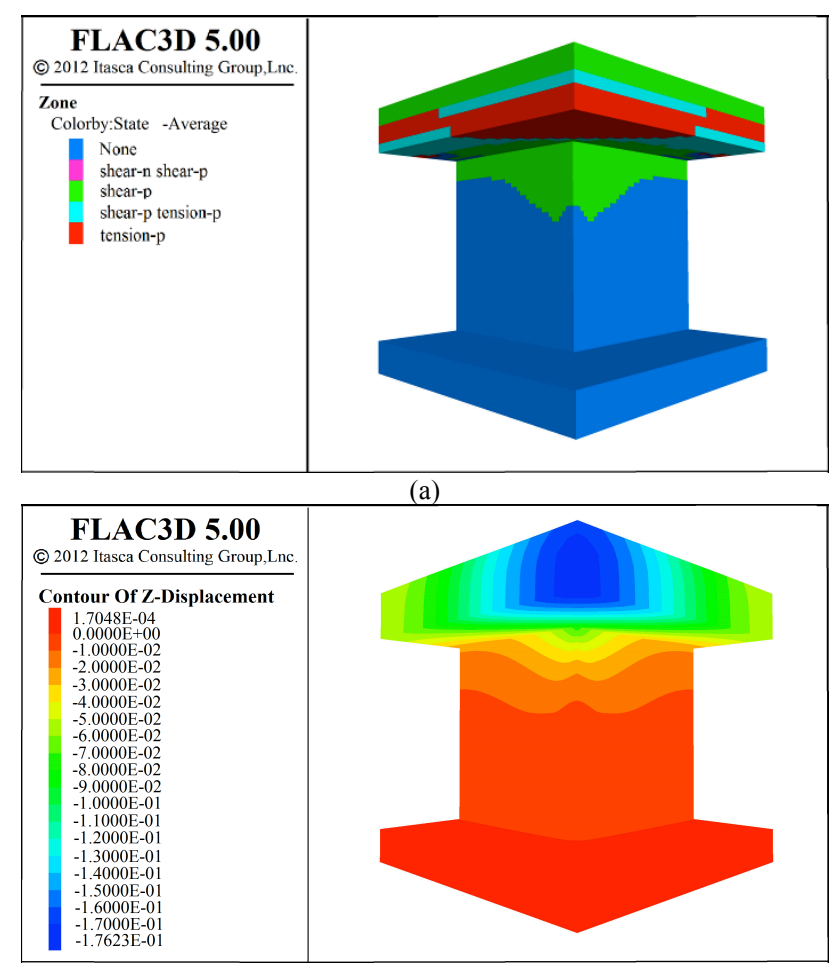

(b)

Fig. 8. Distributions of plastic region and displacement on pillars after spraying. (a) Plastic region. (b) Vertical stress.

\subsubsection{Field test}

A field industrial experiment of sandstone stability control scheme based on shotcrete in Pattison Mine was conducted. The local pillar spalling was effectively controlled after grouting reinforcement, thereby meeting the requirements on safety production of mines. The spraying effect of sandstone pillars in Pattison Mine is shown in Fig. 9.

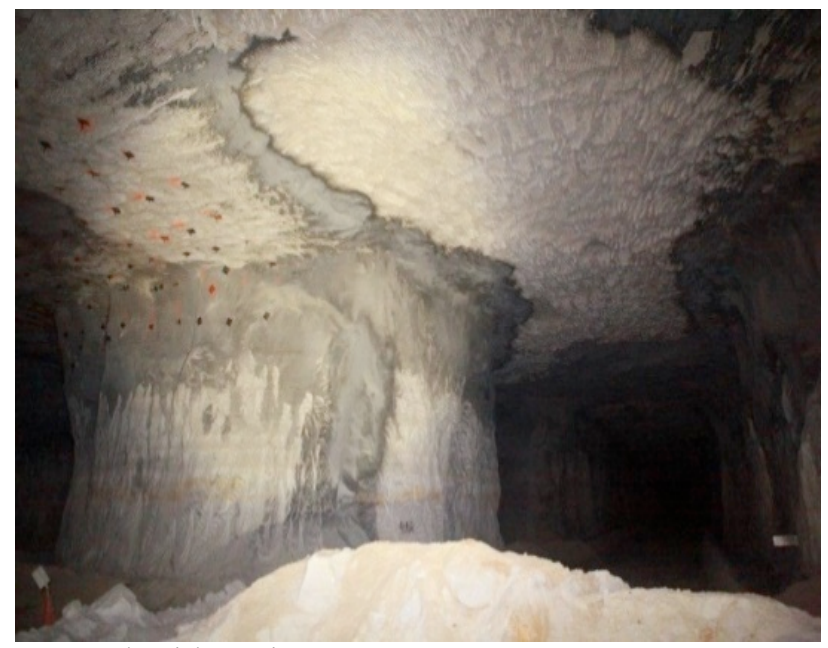

Fig. 9. Industrial experiment

\section{Conclusions}

In this study, cohesion and internal frictional angle are determined the key geotechnical parameters of pillar stability based on theoretical analysis, in order to discuss the influences of the mechanical parameters of rock mass and disclose the internal mechanism of pillar spalling. Next, the stress and deformation distributions of the surrounding rocks on pillars under different cohesion and internal friction angles are analyzed by finite difference analysis. The pillar stability control program by increasing cohesion through shotcrete is formulated. Some conclusions could be drawn, as indicated below.

(1) Stress concentration region is developed and the overburden is increased when the sandstone pillars bear mining-induced stress. Moreover, rock mass on pillars is changed from three-directional into two-directional stress state during room and pillar mining, thereby decreasing the pillar strength and causing shear failures in most regions. An "X-shaped" plastic region is formed on the pillar body.

(2) The cohesion and internal friction angle of sandstone are key factors that influence pillar strength. The horizontal displacement of pillars presents the power functional relations with cohesion and the internal friction angle of rock mass. The plastic failure region of pillars continuously narrows with the independent or simultaneous increase in cohesion and internal friction angle.

(3) The plastic deformation of pillars decreases when the internal friction angle of sandstone increases from $0^{\circ}$ to $60^{\circ}$. However, the deformation control of pillars achieves poor performances after $60^{\circ}$. The plastic deformation of pillars is negatively correlated with cohesion before $1.4 \mathrm{MPa}$. However, the pillar deformation remains the same with the increase in cohesion after 1.4 MPa. Thus, cohesion affects deformation of sandstone pillars mostly when it gradually increases from 0 .

(4) Owing to the high internal friction angle and low cohesion of sandstone, pillar spalling can be effectively controlled by increasing cohesion and confining pressure through shotcrete and increasing pillar strength through improvement of the three-directional stress state of rock mass.

The proposed pillar stability control method by changing the mechanical parameters of rock mass is characterized by the following advantages: simple operation, low cost, and good control over pillar failure. This method lays a foundation to solve other rock strata control problems during room and pillar mining. However, this study did not conduct a quantitative analysis of the influences of spraying support assisted by anchor rod and metal mesh on the mechanical performance of pillars. Further associated studies are thus needed.

\section{Acknowledgements}

The study was supported by National Natural Science Foundation of China (Grant Nos.51504183;51874232; 51804243) and Natural Science Foundation and Scientific Project Foundation of Shaanxi Province (Grant No.2015JQ5132; 17JK0486; 2018TD-038), Open Fund of Anhui Province Key Laboratory of Mining Response, Disaster Prevention and Control in Deep Coal Mine (Grant No. KLDCMERDPC13102).

This is an Open Access article distributed under the terms of the Creative Commons Attribution Licence

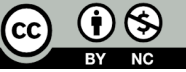


Ding Ziwei, Jia Jindui, Bagherieh Amirhossein, Li Ji and Song Yue/

Journal of Engineering Science and Technology Review 11 (6) (2018) 197 - 205

\section{References}

1. Hudeček, V., Šancer, J., Zubíček V., Golasowski, J., "Experience in the adoption of Room \& pillar mining method in the company OKD a.s., Czech Republic". Acta Montanistica Slovaca, 22(3), 2017, pp.303-312.

2. Zhang, J. X., Huang, P., Zhang, Q., Li, M., Chen, Z. W., "Stability and control of room mining coal pillars-taking room mining coal pillars of solid backfill recovery as an example". Journal of Central South University, 24 (5), 2017, pp.1121-1132.

3. Luo, Y., "Room-and-pillar panel design method to avoid surface subsidence". Mining Engineering, 67(7), 2015, pp.105-110.

4. Bieniawski, Z.T., "In situ strength and deformation characteristics of coal". Engineering Geology, 2(5), 1968, pp.325-340.

5. Wilson, A. H., "A hypothesis concerning pillar stability". Mining Engineering, 131(141), 1972, pp.409- 417.

6. Hustrulid, W.A., "A review of coal pillar strength formulas", Rock Mechanics, 8(2), 1976, pp.115-145.

7. Payne, C. M., "Engineering aspects of the St. Peter sandstone in the Minneapolis-St. Paul area of Minnesota". Master thesis of University of Arizona, USA, 1967, pp.5-15.

8. Dusseault, M. B., Morgenstern, N. R., "Locked sands". Quarterly Journal of Engineering Geology and Hydrogeology, 12(2), 1979, pp.117-131.

9. Dittes, M., Labuz, J. F., "Field and laboratory testing of St. Peter sandstone". Journal of Geotechnical and Geoenvironmental Engineering, 128(5), 2002, pp.372-380.

10. Ranani, R. H., Martin, C. D., "Modeling the progressive failure of hard rock pillars". Tunnelling and Underground Space Technology, 74(2), 2018, pp.71-81.

11. Poulsen, B. A., "Coal pillar load calculation by pressure arch theory and near field extraction ratio". International Journal of Rock Mechanics and Mining Sciences, 47(7), 2010, pp.1158-1165.

12. Wang, H., Poulsen, B.A., Shen, B., Zhue, S., Jiang, Y., "The influence of roadway backfill on the coal pillar strength by numerical investigation". International Journal of Rock Mechanics and Mining Sciences, 48(3), 2011, pp.443-450.

13. Yang, H. S., Kim, W. B., Ali, M.M., "Performance of pillar design in underground stone mines that include discontinuities". Geosystem Engineering, 15(3), 2012, pp.187-194.

14. Guy, R., Kent, M., Rusell, F., "An assessment of coal pillar system stability criteria based on a mechanistic evaluation of the interaction between coal pillars and the overburden". International Journal of Mining Science and Technology, 27(1), 2017, pp.9-15.
15. Jaiswal, A., Shrivastva, B. K., "Numerical simulation of coal pillar strength". International Journal of Rock Mechanics and Mining Science, 46(4), 2009, pp.779-788.

16. Kaiser, P.K., Kim, B., Bewick, R.P., Valley, B., "Rock mass strength at depth and implications for pillar design". Mining Technology, 120(3), 2011, pp.170-179.

17. Dolinar, D.R., Esterhuizen, G.S., "Evaluation of the effect of length on the strength of slender pillars in limestone mines using numerical modeling". In: Proceedings of the 26th International Conference on Ground Control in Mining, Morgantown, USA: ICGCM, 2007, pp.304-313.

18. Esterhuizenn, G. S., Dolina, D. R., Ellenberger, J. L., "Pillar strength in underground stone mines in the United States". International Journal of Rock Mechanics and Mining Science, 48(1), 2011, pp.42-50.

19. Walton, G., Diederichs, M.S., "A mine shaft case study on the accurate prediction of yield and displacements in stressed ground using lab-derived material properties". Tunnelling and Underground Space Technology, 49(3), 2015, pp.98-113.

20. Song, W. D., Cao, S., Fu, J., Jiang, J. G., Wu, F., "Sensitivity analysis of impact factors of pillar stability and its application". Rock and Soil Mechanics, 35(S1), 2014, pp.271-277.

21. Yin, H. S., Wu, A. X., Li, X. W., "Orthogonal polar difference analysis for sensitivity of the factors influencing the ore pillar stability". Journal of China Coal Society, 37(S1), 2012, pp.48-52.

22. Jiang, J. Y., Wang, Y. H., Yan, P., Zhao, Z. H., "Numerical simulation analysis of instability failure of coal pillar in mine room mining". Journal of Shandong University of Science and Technology (Natural Science), 37(5), 2018, pp.27-33.

23. Fu, X.Y., Li, H.Y., Li, F.M., Li, S.G., Zhang, B., Li, H.J.,Wei, L.K., "Mechanism and prevention of strong strata behaviors induced by the concentration coal pillar of a room mining goaf". Journal of China Coal Society, 41(6), 2016, pp.1375-1383.

24. Ghasemim, E., Shahriar, K., "A new coal pillars design method in order to enhance safety of the retreat mining in room and pillar Mines". Safety Science, 50(3), 2012, pp.579-585.

25. Peng, S. S., "Coal Mine Ground Control". New York: John Wiley \& Sons Press, USA, 1978, pp.76-77.

26. Du, X. Z., Lu, J., Morsy, K., Peng, S. S., "Coal pillar design formulae review and analysis". In: Proceedings of the 27th International Conference on Ground Control in Mining, Morgantown, USA: ICGCM, 2010, pp.254-261. 